\title{
Advancing Humanism in Medical Education
}

\author{
Anthony L. Suchman, MD, MA \\ Relationship Centered Health Care, Rochester, NY, USA ; \\ American Academy on Communication in Healthcare, Chesterfield, MO, USA .
}

J Gen Intern Med 22(11):1630-1

DOI: $10.1007 / \mathrm{s} 11606-007-0374-2$

(C) Society of General Internal Medicine 2007

$\mathrm{R}$ achel Naomi Remen has long been a leading advocate for humanism in medicine and for the integration of self into professional practice. She walks the talk. In her books, she relates the story of her own epiphany and transformation, instigated by a serious illness. ${ }^{1,2}$ Through the creation of landmark programs on healing, first for cancer patients and subsequently for practitioners and educators, she has directly or indirectly helped thousands of people engage in their own reflective journeys to reclaim their authenticity and their health.

To spread this process of healing even further, Dr. Remen and her colleagues created The Healer's Art, an elective course in professionalism developed for medical students and faculty. They made the course syllabus widely available (at no cost) and inaugurated a faculty development program for course directors. ${ }^{3}$ Over the 15 years since the course was first introduced, it has been adopted by more than 50 medical schools in North America and around the world.

In this issue of the Journal, a report by Rabow and colleagues presents the first national evaluation of The Healer's Art. ${ }^{4}$ Through the words of first and second year medical students, we learn that even this early in their careers, they experience a divide opening between their personal and professional selves and find themselves pulled towards inauthentic behavior:

I think med students can stray away from the reason they want to be physicians while in med school...

...I felt I had to maintain an image of unwavering ability and confidence.

I stopped feeling human when I started medical school.

Finding a community of kindred spirits, these students were grateful to learn that they were not alone in this struggle and that the personal self is a crucial resource in caring for others, not something to be excluded from their professional lives. They appreciated the opportunity to reflect on personal experiences and to explore the importance of relationships and the meaning of professionalism. Moreover, they felt that the topics addressed by the elective were not addressed anywhere else in their medical school curriculum. In their closing remarks, Rabow and colleagues tell us that more and more schools are adopting the elective and that two schools are preparing to make the course a requirement for all students.

Published online September 22, 2007
The evaluation results are encouraging and important, showing immediate and highly desirable effects of a new curricular component. So now what? If a school is really serious about fostering a humanistic approach among its graduates, it must not only initiate a message of humanism and professionalism with an early course like The Healer's Art but also reinforce that message throughout the 4-year curriculum. Charon, Branch and many others have described curricular elements using group discussions and journaling to foster ongoing reflection on clinical experiences. ${ }^{5,}{ }^{6}$ In the new competencybased curriculum at the Indiana University School of Medicine, every single course in medical school-required or elective, from microbiology to the family medicine clerkship to a fourth year elective in surgical oncology-must explicitly address issues of professionalism, moral reasoning, communication or other core competencies in addition to its primary content. ${ }^{7}$

But even this is not enough. The most powerful influence on students' emerging professional identities and values is the informal curriculum-the way students see people treating each other and the way they themselves are treated. ${ }^{8}$ The finest formal curriculum on humanism can be undermined if cynicism, disrespect, and depersonalization are part of the organizational cultures of the schools, hospitals, practices, and clinics in which they are learning. ${ }^{9}$ So if a school is really serious about fostering a humanistic approach among its graduates, it will foster faculty development programs to disseminate methods for creating supportive and collaborative learning environments. It will choose its students based on their humanistic and relational capacities, not only on their academic performance. It will develop systems of leadership development, feedback, and accountability to assure that its leaders are creating positive working environments for the faculty, staff, and students. It will charge its search committees with assessing the emotional intelligence and relational capacity of candidates for leadership positions. It will provide its standing committees (especially those charged with minding the organizational culture, e.g., committees on professional standards, quality, and academic integrity) with ongoing opportunities to reflect on the values implicit in and propagated by their policies and procedures.

Just such an initiative is now entering its sixth year at Indiana, as the medical school strives to foster an informal curriculum that exemplifies and reinforces the competencies and values of its formal curriculum. ${ }^{10}$ This kind of attention to organizational culture will soon become more commonplace as a result of the Liaison Committee on Medical Education's new accreditation criteria pertaining to the learning environment and informal curriculum. ${ }^{11}$

Thus, we can recognize and celebrate a substantial maturation of methods for advancing humanism in medical education, from in-depth introduction to continuing reflection to the 
fostering of suitable learning environments. Once a wistful dream on the part of a few people on the fringe, this whole domain has now come of age, and everyone-patients, students, and clinicians alike-will be the better for it.

Corresponding Author: Anthony L. Suchman, American Academy on Communication in Health, Chesterfield, MO, USA (e-mail: asuchman@rchcweb.com).

\section{REFERENCES}

1. Remen RN. My Grandfather's Blessing: Stories of Strength, Refuge and Belonging. New York: Riverhead Books; 2000.

2. Remen RN. Kitchen Table Wisdom: Stories that Heal. New York: Riverhead Books; 1997.

3. The Healer's Art: Awakening the heart of medicine. http://www.com monweal.org/ishi/programs/healers_art.html.
4. Rabow M, Wrubel J, Remen RN. Authentic community as an education strategy for advancing professionalism: a national evaluation of the Healer's Art course. JGIM. DOI 10.1007/s11606-007-0274-5.

5. Charon R. Narrative and medicine. New Eng J Med 2004;350:862-4.

6. Branch WT Jr. Use of critical incident reports in medical education: a perspective. J Gen Intern Med. 2005;20:1063-67.

7. Litzelman DS, Cottingham A. The new formal competency-based curriculum and informal curriculum at Indiana University School of Medicine: overview and five-year analysis. Acad Med 2007;82: 410-21.

8. Hafferty FW, Franks R. The hidden curriculum, ethics teaching, and the structure of medical education. Acad Med 1994;69:861-71.

9. Inui TS. A Flag in the Wind: Educating for Professionalism in Medicine. Washington, DC: Association of American Medical Colleges; 2003.

10. Suchman AL, Williamson PR, Litzelman DK, Frankel RM, Mossbarger DL, Inui TS and the Relationship-centered Care Initiative Discovery Team. Toward an informal curriculum that teaches professionalism: transforming the social environment of a medical school. J Gen Intern Med 2004;19:499-502.

11. Liaison Committee on Medical Education. New standards on the learning environment. http://www.lcme.org/standard.htm\#learningenvironment. 